\title{
Service Quality And Determinants Of Customer Satisfaction In Hospitals: Turkish Experience
}

Halil Zaim, Fatih University, Turkey

Nizamettin Bayyurt, Fatih University, Turkey

Selim Zaim, Fatih University, Turkey

\begin{abstract}
Service quality has increasingly been the subject of research in recent years. Parasuraman, Zeithaml, and Berry presented and tested a generic model SERVQUAL to measure the perceived quality of a service. James Carman adapted and applied this instrument for use in the hospital industry. In this study, we use the instrument developed by Carman to collect data from the hospitals in Turkey. The purpose of the study is to examine the important criteria for measuring service quality in the health care industry in Turkey. The relationship between customer satisfaction and serqual measures are investigated for this purpose. In our study customer satisfaction measured by three criteria by asking customers; their future purchase intention, how they evaluate overall service quality and how they see overall quality of the hospital. Service quality was measured by the difference between perceived service and expected service and rated on a seven point Likert scale. Serqual measures consist of 6 criteria; tangibility, reliability, responsiveness, assurance, courtesy, and empathy. The techniques of factor analysis and the logistic regression models are used to investigate the relationships. Like the linear regression analysis, most of the usual statistical methods assume that the residuals, or errors, must follow a normal distribution. If they are not the methods should not be used. Unlike ordinary linear regression, logistic regression does not assume that the dependent variable or the error terms are distributed normally. Also, it doesn't assume that the relationship between the independent variables and the dependent variable is linear. Logistic regression is a variation of ordinary regression which is used when the dependent variable is a categorical variable. The results of our analysis confirm that while tangibility, reliability, courtesy and empathy are significant for customer satisfaction, responsiveness and assurance are not.
\end{abstract}

Keywords: service quality, customer satisfaction, health care, Turkey

\section{INTRODUCTION}

n today's changing, and developing global world, both service and manufacturing companies are confronted with a fundamental business challenge, survival and success in a turbulent and increasingly competitive environment. This competition focuses on before and after sales services rather than products' attributes and manufacturing (1).

Today, service industries are dominant in developed countries even though services are among the fastest growing sector in emerging countries, and the importance of service to the economy continues to increase. Due to phenomenal growth of the service sector in modern society, the importance of service management and service quality is also expected to increase.

The role of service quality is widely recognized as being a critical determinant for the success and survival of an organization in today's competitive environment. Any decline in customer satisfaction due to poor service 
quality would be a matter of concern. Consumers are becoming more aware of rising standards in service, prompted by competitive trends, which have developed higher expectations (2).

In recent years, one of the fastest growing industries in the service sector is the health care industry. In the health care industry, all hospitals provide the same type of service, but they do not provide the same quality of service (3). To achieve service excellence, hospitals must strive for zero defections, retaining every customer that the company can profitably serve. Zero defection requires continuous efforts to improve the quality of the service delivery system (4).

The purpose of the study is to gain a better understanding of the serqual factors, which determine consumers' perceptions of service quality, and to examine the causal relationship between service quality and consumer satisfaction in 12 hospitals in Turkey.

\section{LITERATURE REVIEW}

Service quality has received a significant amount of attention by both researchers and practitioners. It has been defined in a variety of ways. Therefore there is no universal and parsimonious definition of quality. Reeves and Bednar (1994) summarized different definitions of quality as follows: (a) quality as excellence, (b) quality as value, (c) quality as conformance to specification, and (d) quality as meeting or exceeding customer's expectations (5).

The interest in service quality has been influential in contributing significantly to the growth of the general services marketing field. In business literature, the customer's perception of quality has been the major focus in studies completed on service quality. Hence service quality is often conceptualized as the comparison of service expectations with actual performance perceptions (6). On an operational level, research on service quality has been dominated by the SERVQUAL instrument, which is based on a so-called gap model. Gap model is recognized today as a major contribution to the service management literature (7).

SERVQUAL is designed by Parasuraman, Zeithaml, and Berry to measure service quality as perceived by the customer. Parasuraman et al.'s measure of service quality was based on Oliver's disconfirmation model. In the disconfirmation theory, the perception of service quality is conceptualized as a comparison of the expected level of service and the actual service performance. Expectations are the wants of consumers, that is, what they feel a service provider should offer. Perceptions refer to the consumers' evaluation of the service provider (8). Therefore, if the customer's performance perceptions exceed the customer expectations, then the service provider provides quality service. The difference in scores determines the level of service quality.

Figure 1: Model

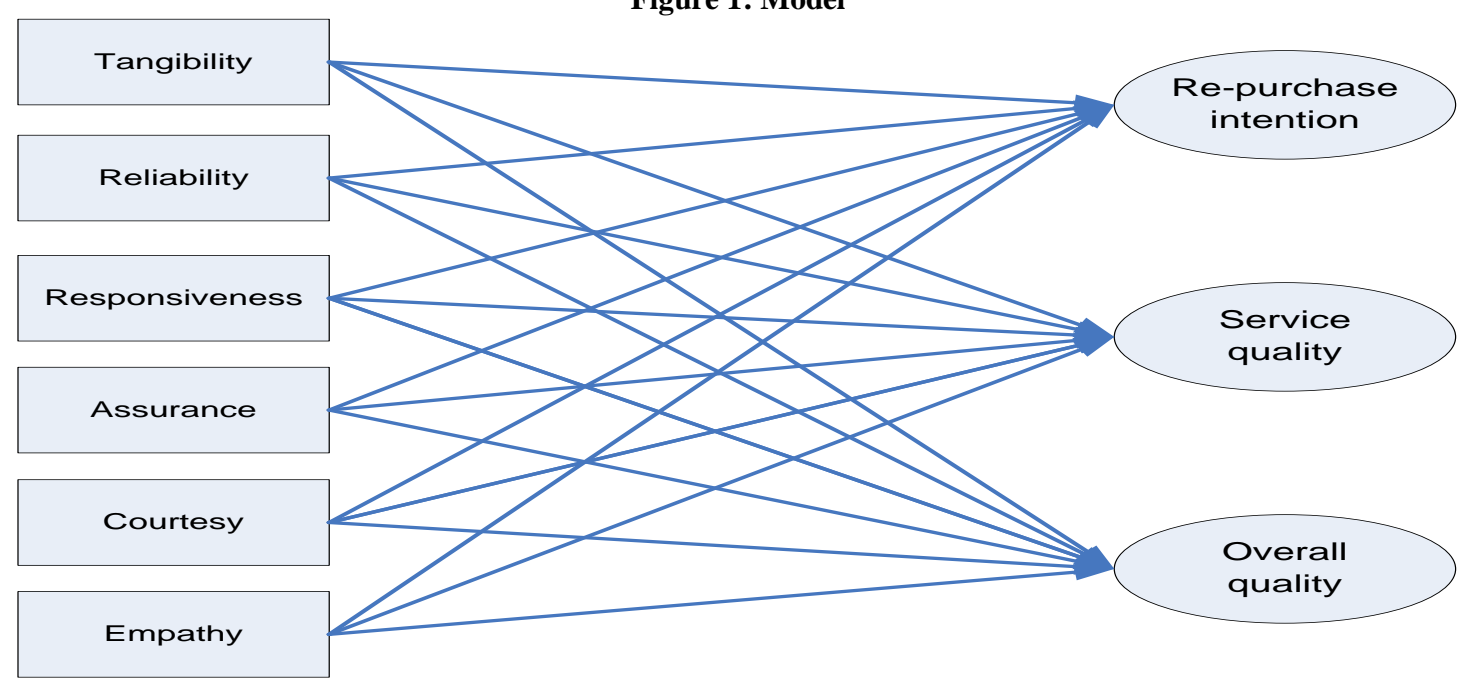


Parasuraman et al. identified ten dimensions, which the customer uses to evaluate the service quality by a factor analysis of 22 questions. Through an empirical test, they developed SERVQUAL from a modification of ten dimensions to five which are tangibles, reliability, responsiveness, assurance, and empathy. After Parasuraman et al. proposed SERVQUAL; several critiques were levied against it. James Carman adapted the original SERVQUAL instrument for use in the hospital industry. The original 22 questions were extended to 34 questions. In this study we used this questionnaire. The determinants of service quality will be broken down into two main categories, namely tangible factors, which refer to technology, physical facilities, personnel, and communication material etc., and intangible factors, which consist of five sub-factors, namely Reliability, Responsiveness, Assurance, Courtesy, and Empathy. Reliability refers to the ability to perform the promised service dependably and accurately. Responsiveness reflects the willingness to help customers and provide prompt service. Assurance reflects the knowledge of employees and their ability to inspire trust and confidence. Courtesy refers to the kind behavior of employees to the customer. Empathy refers to caring, individualized attention the firm provides its customer.

\section{METHODOLOGY}

\section{The sample}

Data for this study was gathered using a questionnaire that was distributed to 400 patients in 12 hospitals in Turkey. 265 useable questionnaires were returned giving a response rate of 66 percent, which was considered satisfactory for subsequent analysis. Two separate questionnaires to be answered by the same patients were developed; one measuring the general expectations of the in-patients who have been under treatment at the hospital and the second one for measuring the perceptions of them related to the service quality performance of the hospital. Each item in the questionnaire was rated on a seven-point Likert scale anchored at the numeral 1 with the verbal statement "Strongly Disagree" and at the numeral 7 with the verbal statement "Strongly Agree". This format has been recommended for the health care survey.

\section{ANALYSIS AND RESULTS}

The first step in the assessment of service quality is the calculation of the gap score. One method for determining the relative importance of service attributes is to measure customer expectations or ideals and calculate the gap between the expected and actual service.

Gap score $=$ Perception score $(\mathrm{P})-$ Expectation score $(\mathrm{E})$

A weighted average for each of the service quality measures with their gap scores is calculated by factor analysis using SPSS. The factor tangibility was extracted from the first 9 questions, reliability from the next 5 questions, responsiveness from next 8 questions, assurance from the questions 23-27, courtesy from 28-32 and empathy is derived from the question 33 and 34. Customer satisfaction measures, Sat1; future purchase behavior, Sat2; overall service quality, and Sat3; overall quality of the hospital were rated on a seven point Likert scale with 1: strongly disagree and 7 strongly agree.

In the study we investigate the importance of SERQUAL measures for the customer satisfaction measures by using logistic regression analysis. Regression analysis is a statistical tool for the investigation of relationships. Like the linear regression analysis, most of the usual statistical methods assume that the residuals, or errors, must follow a normal distribution. If they are not the methods should not be used. Unlike ordinary linear regression, logistic regression does not assume that the dependent variable or the error terms are distributed normally. Also, it doesn't assume that the relationship between the independent variables and the dependent variable is linear. Logistic regression is a variation of ordinary regression which is used when the dependent variable is a categorical variable.

Logistic regression also produces Odds Ratios (O.R.) associated with each predictor value. The "odds" of an event is defined as the probability of the outcome event occurring divided by the probability of the event not occurring. The odds ratio for a predictor is defined as the relative amount by which the odds of the outcome increase (O.R. greater than 1.0) or decrease (O.R. less than 1.0) when the value of the predictor variable is increased by 1.0 units. 
Table 1: logistic regression results

\begin{tabular}{|c|c|c|c|c|c|c|c|c|c|c|c|c|}
\hline & \multicolumn{4}{|c|}{ Sat1 } & \multicolumn{4}{|c|}{ Sat2 } & \multicolumn{4}{|c|}{ Sat3 } \\
\hline & & & Odd & & & & Odd & & & & Odd & \\
\hline & Coef & Std.Err. & R. & $\%$ & Coef. & Std. Err. & R. & $\%$ & Coef. & Std. Err. & R. & $\%$ \\
\hline tangibility & 0.17 & 0.17 & 1.18 & 18 & 0.21 & 0.17 & 1.24 & 24 & $0.56^{*}$ & 0.17 & 1.75 & 75 \\
\hline reliability & 0.2 & 0.2 & 1.22 & 22 & 0.12 & 0.2 & 1.12 & 12 & $0.41 *$ & 0.19 & 1.51 & 51 \\
\hline responsiveness & 0.26 & 0.28 & 1.29 & 29 & 0.36 & 0.28 & 1.43 & 43 & -0.07 & 0.26 & 0.94 & -6 \\
\hline assurance & 0.19 & 0.22 & 1.2 & 20 & 0.17 & 0.22 & 1.18 & 18 & -0.27 & 0.21 & 0.76 & -24 \\
\hline courtesy & $0.49 *$ & 0.25 & 1.63 & 63 & 0.38 & 0.24 & 1.47 & 47 & $0.83 *$ & 0.25 & 2.29 & 129 \\
\hline empathy & 0.36 & 0.22 & 1.43 & 43 & $0.44 *$ & 0.21 & 1.55 & 55 & 0.21 & 0.2 & 1.23 & 23 \\
\hline Number of obs $=265$ & $\begin{array}{l}\text { LR chi } \\
\text { Prob > } \\
\text { Pseudo } \\
\text { Log lik }\end{array}$ & $\begin{array}{l}(6)=98 \\
\text { hi } 2=0.1 \\
R 2=0.1 \\
\text { lihood }=\end{array}$ & $\begin{array}{l}4 \\
00 \\
04 \\
79.44\end{array}$ & & $\begin{array}{l}\text { LR chi2 } \\
\text { Prob > } \\
\text { Pseudo } \\
\text { Log lik }\end{array}$ & $\begin{array}{l}(6)=101 \\
\text { hi } 2=0.0 \\
\text { R2 }=0.15 \\
\text { lihood }=-2\end{array}$ & & & $\begin{array}{l}\text { LR chi2 } \\
\text { Prob > } \\
\text { Pseudo } \\
\text { Log lik }\end{array}$ & $\begin{array}{ll}(6) & =1 \\
h i 2 & =0 \\
\text { R2 } & =0 \\
\text { lihood } & =-3\end{array}$ & $\begin{array}{l}0.84 \\
000 \\
428 \\
2.68\end{array}$ & \\
\hline
\end{tabular}

*; significant at $5 \%$ level

$\%$; percent change in odds for unit increase in $\mathrm{X}$

Ordinal logistic regression was applied in the study with dependent variables; sat1, sat 2 and sat 3 and independent variables; serqual factors. In the table we see that 265 observations were used in the analysis. The likelihood ratio chi-squares of three analysis with the p-values of 0.0000 tell us that our models are statistically significant, as compared to model with no predictors. In the table we see the coefficients of serqual factors, their standard errors, odds ratios and \% columns which show the percent change in odds for unit increase in serqual factors.

The statistically significant serqual factors at $5 \%$ level of significance are courtesy for sat1, empathy for sat 2 and tangibility, reliability and courtesy for sat3. The estimates in the output are given in units of ordered logits, or ordered $\log$ odds. So for courtesy, we would say that for one unit increase in courtesy (i.e., going from 1 to 2), we expect a 0.49 increase in the log odds of sat1, given all of the other variables in the model are held constant. For one unit increase in empathy we expect a 0.44 increase in the $\log$ odds of sat 2 , and for one unit of increase in tangibility, reliability and courtesy, we expect $0,56,0,41$ and 0,83 increase in the log odds of sat 3 respectively, given all of the other variables in the model are held constant.

We would interpret odds ratios or percentage column instead of coefficients. For, courtesy we would say that for one unit increase in courtesy, (i.e., going from 1 to 2), the odds of "strongly agree" for future purchase (sat1=7) versus the combined scales $($ sat $1=1,2 \ldots, 6)$ is 1,63 greater $(\% 63$ increase in the odds for unit increase in courtesy), given that all of the other variables in the model are held constant. For, empathy we would say that for one unit increase in empathy, (i.e., going from 1 to 2), the odds of "strongly agree" for overall service quality (sat $2=7$ ) versus the combined scales (sat $2=1,2 \ldots, 6)$ is 1,55 greater ( $\% 55$ increase in the odds), given that all of the other variables in the model are held constant. Similarly, one unit increase in tangibility, reliability or courtesy the odds of "strongly agree" for overall satisfaction (sat3=7) versus the combined scales (sat3=1,2..,6) are $1,75,1,51$ and 2,29 greater respectively ( $\% 75, \% 51, \% 129$ increase in the odds), given that all of the other variables in the model are held constant

\section{CONCLUSION AND THE MANAGERIAL IMPLICATION:}

In this paper, we examined the relationship between service quality and customer satisfaction in the hospital environment in Turkey. The ordinal logistic regression technique was used for testing the framework of the relationship among the variables.

The results of the analysis give substantial support for the multi-dimensional view for the construct. Although we used the instrument designed by Parasuraman et.al., we found that our dimensions differed to some extent from the dimensions found by these researchers. For example, while tangibility, reliability, courtesy and empathy were important criteria for customer satisfaction in this study, the responsiveness, and assurance factors were not identified as direct determinants of service quality. 
One of the more pressing challenges the health care providers is to develop a better understanding of the key dimensions constituting health care quality and valid approaches to their measurement. However, there is a conceptual gap among scholars in conceptualizing service quality. In addition, there is considerable discrepancy among the existing scales in terms of what to measure and how to measure service quality. This study was conducted to determine important criteria for measuring service quality in the health care industry in Turkey.

To deliver a high quality service and to get high customer satisfaction, we believe that strong managerial orientations should be introduced in the hospitals. Unfortunately, our experiences suggest that modern managerial practices have not been introduced in most hospitals in Turkey. This situation may be attributed partly to the fact that the control of hospital management remains in the hands of physicians who are trained mainly to heal the afflicted, not to manage and administer hospital operations.

When physicians stop competing for administrative positions and leave this position to the managers who have enough managerial skill and talent, the service quality of Turkish hospitals will increase.

\section{AUTHOR INFORMATION}

Halil Zaim has received his B.S. degree in Economics, MA in Social Politics of EU, and Ph.D. in Labour Economics from Istanbul University. Zaim has been serving as an associated professor in the Department of Management at Fatih University. He is also the director of Continuous Education Center in the same university. Halil Zaim has published over 30 articles and papers in various journals and congress proceedings. His current scholarly interests focus on knowledge management, intellectual capital and human resource management. Zaim reviews papers for a variety of journals in his field

Nizamettin Bayyurt has received his B.S. degree in Mathematics from Middle East Technical University and his $\mathrm{Ph} . D$. degree in Quantitative Methods from Istanbul University. Bayyurt has been serving as an assistant professor in the department of Management at Fatih University. His teaching and research interests are on quantitative methods, statistics, multivariate data analysis, business performance and multiple criteria decision making. Bayyurt has published over 30 articles and papers in various journals and congress proceedings. Bayyurt is the editor of European Journal of Economic and Political Studies (EJEPS), and in the editorial board of Euro-Asian Journal of Business and Economics (EJBE). He is a member of Industrial Management and Development Associations (IMDA), Statisticians Society in Turkey, Multi Criteria Decision Making (MCDM), European Chapter on Combinatorial Optimization (ECCO).

Selim Zaim has received his B.S. degree in Mechanical Engineering from Istanbul Technical University and his $\mathrm{Ph}$.D. degree in Production and Operations Management from Istanbul University. Selim Zaim has been serving as a professor in the Department of Management at Fatih University. Zaim has published over 80 articles and papers in various journals and congress proceedings. His current scholarly interests focus on multivariate data analysis, supply chain management, data mining and multi-criteria decision making. Zaim reviews papers for a variety of journals and also serves on the editorial review board of Economy \& Business e-Journalnet and Strategic Outsourcing, An International Journal. He is a member of Industrial Management and Development Associations and Quality Association in Turkey (KALDER).

\section{REFERENCES}

1. Eugene Sivadas and Jamie L. Baker-Prewitt. (2000), "An examination of the relationship between service quality, customer satisfaction, and store loyalty", International Journal of Retail \& Distribution Management, Vol. 28, No. 2, pp.73-82.

2. Ugur yavas; Donald J. Shemwell. (2001), "Modified importance-performance analysis: an application to hospitals", International Journal of Health Care Quality Assurance, Vol. 14 No.3, pp.104-110.

3. Puay Cheng Lim; Nelson K.H. Tang. (2000), "The development of a model for total quality healthcare", Managing Service Quality, Vol. 10 No.2, pp.103-111.

4. Puay Cheng Lim; Nelson K.H. Tang. (2000), "Modified importance-performance analysis: an application to hospitals", International Journal of Health Care Quality Assurance, Vol. 14 No.3, pp.104-110. 
5. Reeves, C.A. Bednar, D.A. (1994), "Defining quality: Alternatives and implications". Academy of management Review, Vol.19, pp.419-445.

6. Bloemer Josee ; Ruyter de Ko ; Wetzels martin. (1999), "Linking perceived service quality and service loyalty: a multi-dimensional perspective", European Journal of Marketing, Vol. 33, No.11/12, pp.10821106.

7. Parasuraman A.; Valarie A. Zeithaml; Leonard L. Berry, (1985), “A conceptual model of service quality and its implications for future research", Journal of Marketing, Vol.49, fall, pp.41-50.

8. Parasuraman A.; Valarie A. Zeithaml; Leonard L. Berry. (1988), "SERVQUAL: A multiple item scale for measuring customer perceptions of service quality", Journal of Retailing, Vol. 64, spring, pp. 12-40. 


\section{APPENDIX: QUESTIONNAIRE}

\author{
Tangibility: \\ 1. They should have up to date equipment and technology \\ 2. Their physical facility should be visually appealing \\ 3. Bathrooms should be very clean \\ 4. Rooms should be clean \\ 5. Meals should be attractive. \\ 6. Food should have right temperature. \\ 7. Nurses should respect privacy. \\ 8. Room should be quite. \\ 9. Parking should be convenient
}

\section{Reliability:}

10. Food should be delivered by a certain time.

11. When staff of the institutions promise to do something by a certain time, they should do it.

12. They should keep patients' records accurately.

13. Hospital charges should be accurate.

14. When the staff promises to perform certain services, they should provide them.

\section{Responsiveness:}

15. Patients who will be discharged should expect prompt service from employees of the hospital for the discharging operations.

16. Patients should expect prompt services from nurses when the patients need them.

17. Patients who come to hospital should expect prompt service from employees of the hospital for the admission operation.

18. Employees of the hospital should always be willing to help their patients.

19. Employees of the hospitals should explain customer's question appropriately about the discharge process.

20. Employees of the hospital should explain customer's question appropriately about any procedure.

21. Treatment should be explained to the patient very clearly.

22. Discharge should be explained to the patient's family.

\section{Assurance:}

23. Customer should be able to trust nurses of the hospital.

24. Patient should be secure that they recovered well before they are dischsrged.

25. Patients should be able to trust billing.

26. Patient should be able to feel safe in their transactions with these institution's employees.

27. Patients should be able to feel safe that nurses are knowledgeable.

\section{Courtesy:}

28. Employees should be polite during admissions procedure.

29. Employees should be polite during housekeeping process.

30. Nurses' behavior should be very polite against customers.

31. Nurses should be cheerful.

32. Visitors should be treated well.

$\begin{array}{lllllll}1 & 2 & 3 & 4 & 5 & 6 & 7 \\ 1 & 2 & 3 & 4 & 5 & 6 & 7 \\ 1 & 2 & 3 & 4 & 5 & 6 & 7 \\ 1 & 2 & 3 & 4 & 5 & 6 & 7 \\ 1 & 2 & 3 & 4 & 5 & 6 & 7 \\ 1 & 2 & 3 & 4 & 5 & 6 & 7 \\ 1 & 2 & 3 & 4 & 5 & 6 & 7 \\ 1 & 2 & 3 & 4 & 5 & 6 & 7 \\ 1 & 2 & 3 & 4 & 5 & 6 & 7\end{array}$

$\begin{array}{lllllll}1 & 2 & 3 & 4 & 5 & 6 & 7 \\ 1 & 2 & 3 & 4 & 5 & 6 & 7 \\ 1 & 2 & 3 & 4 & 5 & 6 & 7 \\ 1 & 2 & 3 & 4 & 5 & 6 & 7 \\ 1 & 2 & 3 & 4 & 5 & 6 & 7\end{array}$

$\begin{array}{lllllll}1 & 2 & 3 & 4 & 5 & 6 & 7\end{array}$

$\begin{array}{lllllll}1 & 2 & 3 & 4 & 5 & 6 & 7\end{array}$

$\begin{array}{lllllll}1 & 2 & 3 & 4 & 5 & 6 & 7\end{array}$

$\begin{array}{lllllll}1 & 2 & 3 & 4 & 5 & 6 & 7\end{array}$

$\begin{array}{lllllll}1 & 2 & 3 & 4 & 5 & 6 & 7\end{array}$

$\begin{array}{lllllll}1 & 2 & 3 & 4 & 5 & 6 & 7\end{array}$

$\begin{array}{lllllll}1 & 2 & 3 & 4 & 5 & 6 & 7\end{array}$

$\begin{array}{lllllll}1 & 2 & 3 & 4 & 5 & 6 & 7\end{array}$

$\begin{array}{lllllll}1 & 2 & 3 & 4 & 5 & 6 & 7\end{array}$

$\begin{array}{lllllll}1 & 2 & 3 & 4 & 5 & 6 & 7\end{array}$

$\begin{array}{lllllll}1 & 2 & 3 & 4 & 5 & 6 & 7\end{array}$

$\begin{array}{lllllll}1 & 2 & 3 & 4 & 5 & 6 & 7\end{array}$

$\begin{array}{lllllll}1 & 2 & 3 & 4 & 5 & 6 & 7\end{array}$ 


\section{Empathy:}

33. Patients should expect employees to know their needs.

34. Patients should expect nurses to show personal attention to the patients.

Satisfaction Measurements

In the next year my use of .... hospital.

My feeling towards....hospitals' service can be best described.

The overall quality of .... hospital. $\begin{array}{lllllll}1 & 2 & 3 & 4 & 5 & 6 & 7\end{array}$

$\begin{array}{lllllll}1 & 2 & 3 & 4 & 5 & 6 & 7\end{array}$

$\begin{array}{lllllll}1 & 2 & 3 & 4 & 5 & 6 & 7\end{array}$

$\begin{array}{lllllll}1 & 2 & 3 & 4 & 5 & 6 & 7\end{array}$

$\begin{array}{lllllll}1 & 2 & 3 & 4 & 5 & 6 & 7\end{array}$

\section{NOTES}

